\title{
Incidence-Proportion of Maternal Near-Misses and Associated Factors in Southwest Ethiopia: A Prospective Cross-Sectional Study
}

This article was published in the following Dove Press journal: International Journal of Women's Health

\author{
Yayehyirad Yemane \\ Firew Tiruneh (D) \\ Department of Midwifery, College of \\ Health Sciences, Mizan-Tepi University, \\ Mizan Teferi, Ethiopia
}

Background: Pregnancy-related morbidity and mortality continue to have a serious impact on the lives of women all over the world. Women in sub-Saharan Africa accounted for nearly two-thirds of global maternal deaths. The World Health Organization recommends monitoring maternal near-miss provides better information regarding the quality of maternal health care, on which to base action to prevent further death. Accordingly, this study sought to assess the incidence-proportion of maternal near-miss and its risk factors. We have also seen the near-miss-to-mortality ratio and overall maternal mortality index.

Methods: An institution-based prospective cross-sectional study was carried out from February 6, 2017 to March 6, 2017, using the WHO criteria for maternal near-misses at the three randomly selected public hospitals. About 845 participants were enrolled in the study with systematic random sampling techniques. WHO multi-country survey on maternal and neonatal health tool was used. Descriptive statistics and bivariate logistic regression analysis were done. Variables with p-value $<0.2$ in the bivariate analysis were transferred to multivariable analysis, and during multivariate logistic regression analysis, variables with P-value $<0.05$ were considered as statistically significant with $95 \%$ CI.

Results: There were 5530 live births, 210 maternal near-misses, 17 maternal deaths, and 364 maternal near-miss events. The overall proportion of maternal near-miss is $24.85 \%$. Besides, the ratio of maternal near-misses to maternal mortality was $12.35: 1$, and the overall mortality index was $7.48 \%$. Parity, residence, a distance of maternal home from the hospital, ANC follow-up, duration of labor, and administration-related problems were found to have statistically significant associations.

Conclusion: The incidence-proportion of maternal near-misses is relatively high when compared against the national target and to other regional studies. Besides, with all its limitations, the outcome indicators and outcome measures in this study seem to suggest optimum care is being given to mothers who suffered from life-threatening complications.

Keywords: incidence-proportion, near-misses, mortality index, near-miss ratio, delivery

\section{Introduction}

Worldwide, about 140 million births take place every year. Pregnancy-related morbidity and mortality continue to have a serious impact on the lives of women all over the world; particularly in developing countries. In the last two decades, maternal mortality has dropped by $38 \%$ worldwide. ${ }^{1}$ However, approximately 810 women are still dying every day from complications during pregnancy and delivery. ${ }^{2}$ Almost $94 \%$ of the deaths occur in low- and low-middle-income countries. Sub-Saharan Africa and Southern Asia share the greatest burden of maternal deaths, $86 \%$ of the global total in $2017 .^{3}$
Correspondence: Firew Tiruneh Department of Midwifery, College of Health Sciences, Mizan-Tepi University, Po Box 260 Mizan University, Mizan Teferi, Ethiopia

Tel +251 91 7830101

Email mtu2012x@gmail.com
International Journal of Women's Health 2020: I 2 | I 25-I I 34

I 125 
The primary indicator of maternal health care quality is the maternal mortality ratio (MMR). ${ }^{4}$ However, monitoring only maternal death at health facility does not provide a complete source of information on which to base steps to prevent further deaths. ${ }^{5}$ Thus, women who survive severe complications during pregnancy, childbirth, and the postpartum period could serve as surrogates to help us gain a better understanding of the set of conditions and preventable factors that contribute to a maternal death. ${ }^{6}$

Women who experienced severe complications often escape death either by chance or the quality of care received. $^{7}$ These women are called maternal near-miss. Maternal near-miss is defined as a case of women who nearly died but survived a complication that has occurred during pregnancy, delivery, or in the first 42 days after delivery. The World Health Organization (WHO) recommends that the maternal near-miss approach should be considered in national plans for improving maternal health care. ${ }^{8}$ Women in sub-Saharan Africa alone accounted for nearly two-thirds of global maternal deaths. ${ }^{8}$

Ethiopia is one of the sub-Saharan Africa countries. In 2017, according to the Fragile States Index, Ethiopia was among the 15 countries considered to be "very high alert" or "high alert" being a fragile state. ${ }^{9}$ This evidence suggests the risk of maternal mortality in the country. Ethiopian demographic health survey (EDHS) vital health indicators revealed for every maternal death, $10-15 \%$ of the women develop disability from pregnancy and pregnancy-related complications. ${ }^{10}$ According to the Central Intelligence Agency, the estimated maternal mortality ratio in Ethiopia is around 401 deaths/100,000 live births. ${ }^{11}$ Reducing maternal mortality to less than 70 per 100,000 live births by 2030 is one of the key sustainable development goals. ${ }^{12}$

Few studies were conducted regarding maternal nearmiss in Ethiopia. ${ }^{12-15}$ However, their result is imprecise for our study area. Because the sociocultural context considered in these studies were quite different from ours. For instance, giving birth alone in the jungle and avoiding male skilled birth attendant is the harmful culture practiced in the study area. To the best of researchers' knowledge, there are no published studies in the study area. We, therefore, sought to assess the burden of severe maternal morbidity by calculating the MNM and factors associated with MNM. The finding will help to monitor the magnitude and trend of maternal near-miss, so that action can be taken to realize the sustainable development goal.

\section{Methods}

\section{Aim}

We aimed to determine the incidence proportion of maternal near-miss and factor associated with maternal nearmiss in public facilities of SNNPR, Southwest Ethiopia.

\section{Study Design and Setting}

We conducted an institution-based prospective crosssectional study from February 6, 2017 to May 6, 2017. This period is a time in which study subjects were recruited and data were collected from study subjects. The study was conducted in three selected public hospitals namely Mizan Aman Hospital, Tepi Hospital, and Gebretsadik Shawo Hospital located in Bench-Maji, Sheka, and Kaffa Zones of SNNPR, Southwest Ethiopia, respectively. These Hospitals are the only high-level hospitals in the area serving more than 2.4 million populations. These hospitals provide a 24-hour maternal and child health services, emergency service intensive care service, reproductive, and adult health services. All women with risk factors or obstetric complications are referred to these hospitals from nearby health centers.

\section{Participants}

A sample size of 845 was estimated using a technique of determining sample size for population proportion in twostage sampling. ${ }^{16}$ Study subjects were included from women who were admitted to selected public health institutions for early pregnancy complications, for delivery service, or within 42 days after delivery with systematic random sampling techniques. We excluded women with complication due to accidental or incidental causes; which was not caused or aggravated by the pregnancy or the process of delivery. These criteria are recommended by WHO so that the same classification of underlying causes is used for both maternal near-misses and deaths. This consistency and a set of near-miss indicators enable assessments of the quality of care provided to pregnant women.

\section{Data Collection}

Data were collected by six senior BSc midwives who were trained for data collection by the principal investigator. Data collectors screened all women admitted to the delivery unit, emergency unit, intensive care unit, gynecology ward, and postnatal ward according to the inclusion criteria. WHO multi-country survey on maternal and neonatal 
health was used to define maternal near-miss. Data collection was done through record review and interview with the patient and accompanying family members or any other relevant person involved in her care. All interviews were taken into the local language in a semi-structured questionnaire prepared by a language expert.

Data on socio-demography, obstetrical history, and screening for near-miss were collected through an interview while data regarding diagnosis, laboratory finding, treatment and management, and data for the near-miss criterion-based clinical audit were collected by record review. On top of these data which were used to calculate hospital access, intrahospital care indicators, and process indicators were collected from Hospital administrators. All women included in the study were followed up until discharge and data were collected at the point of exit from the hospital. The data collection process was supervised by the principal investigator.

To ensure data quality, data collectors and supervisors took 2 days of intensive training on data collection. A pretest was done on $5 \%$ of the samples in the hospital not selected for the study. The Principal investigator and supervisors made frequent checks for consistency and completeness of collected data and appropriate corrections were made on the spot. Data were coded and double entry was made in software.

\section{Data Processing and Analysis}

Data were coded and entered into EpiinfoTM V 7.2 then transported to SPSS version 20 statistical package. Data processing and cleaning were made to examine the nature of the data. A multicollinearity test was done and very little was found. Before bivariate analysis was done the primary outcome measures, outcome indicators, near-miss indicators, Hospital access indicators, and lastly, intrahospital care indicators were calculated. Descriptive statistics such as frequencies, percentage, mean, median, SD, and range were used to summarize data. Bivariate logistic regression was used to determine the association between each independent variable with the dependent variable. Then, multivariable logistic regression analysis was done by taking all variables with $\mathrm{p}$-value $<0.2$ on binary logistic regression into the model at the same time, a p-value of 0.05 or less and adjusted odds ratio (AOR) with $95 \%$ confidence interval was used to determine a variable that is an independent predictor of the outcome variable. A backward stepwise approach was used. HosmerLemeshow goodness of fit test was carried out to ensure whether the data were conflicted with assumptions made by the model or not.

\section{Operational Definition}

- Maternal near-miss refers to a woman who nearly died but survived a complication that occurred during pregnancy, childbirth, or within 42 days of termination of pregnancy.

- Maternal near-miss event refers to any of the events that occurred as specified on the WHO MCSMC tool.

- Maternal near-miss case refers to a mother who experiences one or more of the events.

- Women with life-threatening conditions (WLTC) refers to all women either who qualified as having maternal near-miss or who died $($ WLTC $=$ MNM + MD)

- Maternal death (MD) is the death of a woman while pregnant or within 42 days of termination of pregnancy.

- Live birth (LB) refers to the complete expulsion the product of conception with evidence of life from its mother irrespective of the gestational age.

- Mortality index (MI) refers to the number of maternal deaths divided by the number of women who experienced life-threatening conditions, expressed as a percent. $[\mathrm{MI}=\mathrm{MD} /(\mathrm{MNM}+\mathrm{MD})]^{8}$

- Maternal near-miss incidence ratio (MNMIR) refers to the number of maternal near-miss cases per 1000 live births; the numerator being the magnitude of MNM and the denominator is live births conducted at the hospitals.

- Cultural malpractice refers to a cultural practice in the area which brings a serious harm on the mother or on the fetus, for instance being isolated alone in jungle for labour.

\section{Result}

\section{Socio-Demography Characteristics}

During the study period, 17 women died and 210 maternal near-misses occurred. In the selected hospitals a total of 5530 live births were reported. Demographic data are indicated in Table 1. The mean age at enrollment in the study was 26.52 ( \pm 5.819 years). Almost all (93.85\%) of the study participants were married. A quarter of the respondents $(25.56 \%)$ were homemakers whereas $23.19 \%$ were traders. More than half $(62.48 \%)$ of the study participants were from rural areas while $37.5 \%$ were from urban areas. 
Table I Socio-Demographic Characteristics of Study Participants in the Selected Hospitals, SNNPR, Southwest Ethiopia, 2017

\begin{tabular}{|c|c|c|c|}
\hline Variables & $N=845$ & Frequency & $\begin{array}{l}\text { Percent } \\
\text { (\%) }\end{array}$ \\
\hline Marital status & $\begin{array}{l}\text { Single } \\
\text { Married } \\
\text { Divorced }\end{array}$ & $\begin{array}{l}40 \\
793 \\
12\end{array}$ & $\begin{array}{l}4.70 \\
93.85 \\
1.42\end{array}$ \\
\hline Age (years) & $\begin{array}{l}15-18 \\
20-24 \\
25-29\end{array}$ & $\begin{array}{l}382 \\
432 \\
31\end{array}$ & $\begin{array}{l}45.20 \\
51.10 \\
3.70\end{array}$ \\
\hline Religion & $\begin{array}{l}\text { Orthodox } \\
\text { Muslim } \\
\text { Protestant } \\
\text { Catholic }\end{array}$ & $\begin{array}{l}470 \\
99 \\
269 \\
7\end{array}$ & $\begin{array}{l}41.00 \\
8.60 \\
23.50 \\
0.60\end{array}$ \\
\hline Ethnicity & $\begin{array}{l}\text { Bench } \\
\text { Amhara } \\
\text { Keffa } \\
\text { Sheka } \\
\text { Tigre } \\
\text { Oromo } \\
\text { Unable to read and } \\
\text { write }\end{array}$ & $\begin{array}{l}202 \\
154 \\
212 \\
205 \\
28 \\
44 \\
245\end{array}$ & $\begin{array}{l}23.91 \\
18.22 \\
25.08 \\
24.26 \\
3.31 \\
5.20 \\
28.99\end{array}$ \\
\hline Education & $\begin{array}{l}\text { Able to write and } \\
\text { read } \\
\text { College graduated }\end{array}$ & $\begin{array}{l}425 \\
175\end{array}$ & $\begin{array}{l}50.29 \\
20.71\end{array}$ \\
\hline $\begin{array}{l}\text { Occupational } \\
\text { status }\end{array}$ & $\begin{array}{l}\text { Farmer } \\
\text { Trader } \\
\text { Housewife } \\
\text { Government } \\
\text { employees } \\
\text { Daily laborer } \\
\text { Other }\end{array}$ & $\begin{array}{l}216 \\
192 \\
173 \\
165 \\
\\
55 \\
42\end{array}$ & $\begin{array}{l}25.56 \\
22.72 \\
20.47 \\
19.53 \\
\\
6.51 \\
4.97\end{array}$ \\
\hline Residence & $\begin{array}{l}\text { Urban } \\
\text { Rural }\end{array}$ & $\begin{array}{l}317 \\
528\end{array}$ & $\begin{array}{l}37.50 \\
62.48\end{array}$ \\
\hline $\begin{array}{l}\text { Distance } \\
\text { traveled }\end{array}$ & $\begin{array}{l}\leq 10 \mathrm{~km} \\
>11 \mathrm{~km}\end{array}$ & $\begin{array}{l}275 \\
570\end{array}$ & $\begin{array}{l}32.54 \\
67.45\end{array}$ \\
\hline
\end{tabular}

About $67.45 \%$ traveled more than $>11 \mathrm{~km}$ to access health facilities and the median distance was $30 \mathrm{~km}$ with an interquartile range of $25 \mathrm{~km}$.

\section{Obstetric and Other Characteristics}

Of the participants included in the study, nearly, $86 \%$ of the women came to the health facility on their own decision while $14.08 \%$ of the women were referred from nearby health centers. The majority $(63.63 \%)$ of participants had Spontaneous Vertex Delivery with or without episiotomy, 23.52\% underwent Cesarean section, 8.95\% received manual vacuum aspiration (MVA) and 3.9\% received forceps delivery. Out of $18 \%$ treated medically, $71.71 \%$ treated with antibiotics, $13.76 \%$ treated with anticonvulsion drugs, $18.35 \%$ with anti-hypertensive drugs, and $7.34 \%$ were given both anti-convulsant and antihypertensive drugs. The comparison of obstetric characteristics for mothers with a near-miss and without a near-miss is indicated in Table 2 .

Nearly $5 \%$ of the total respondents had encountered medical personnel-related problems, of these $38.09 \%$ had delayed diagnosis (more than 12 hours), 40.48\% got delayed definitive treatment after diagnosis, $14.29 \%$ were not assessed by a senior doctor, and $7.14 \%$ were not monitored properly. Around 17\% faced administrationrelated problems, of this majority $(81.58 \%)$ suffered from Lack of life-saving drugs, $16.67 \%$ suffered from Lack/ inefficient transportation and communication, and $1.75 \%$ of the participants did not receive blood products when needed.

\section{Maternal Near-Misses}

There were a total of 5530 live births and 17 maternal deaths. During the study period, 364 maternal near-miss events and 210 maternal near-miss cases occurred, which showed that 154 women had more than one near-miss event. Depending on the criteria used, the maternal nearmiss incident proportion was $24.85 \% \quad(95 \%$ $\mathrm{CI}=21.93-27.77)$. Besides, the ratio of maternal nearmisses mortality was $12.35: 1$, and the overall mortality index was $7.48 \%$. Regarding indicators proposed by the WHO to describe maternal events (see Table 3).

Out of the 210 maternal near-misses, $23.33 \%$ were diagnosed at referring institutions, $10 \%$ were diagnosed soon at arrival, $49.05 \%$ were diagnosed within 12 hours of arrival and $17.62 \%$ were diagnosed after 12 hours of arrival. Hemorrhage accounted for the most common event $32.86 \%$, followed by severe pre-eclampsia $23.33 \%$, sepsis $19.52 \%$, uterine rupture $15.71 \%$, and eclampsia $8.57 \%$ (Figure 1). Around 16.19 organ dysfunction has been reported.

The mortality index for each cause is presented in Table 4. During the study period, majority $(60.48 \%)$ of near-misses were managed by midwives, $16.67 \%$ by Integrated Emergency Surgery and Obstetric Care (IESOC) professionals, $12.86 \%$ by general practitioners and a few (10\%) by gynecologists and obstetricians. 
Table 2 Obstetric Characteristics of the Study Participants in Selected Public Health Institutions, SNNPR, Southwest Ethiopia, 2017

\begin{tabular}{|c|c|c|c|c|c|}
\hline \multirow[t]{2}{*}{ Variables } & & \multicolumn{2}{|c|}{ Women with Near-Miss } & \multicolumn{2}{|c|}{ Women without a Near-Miss } \\
\hline & & Frequency & Percent (\%) & Frequency & Percent (\%) \\
\hline \multirow[t]{3}{*}{ Parity } & Nulliparous & 17 & 8.10 & 112 & 17.64 \\
\hline & Primiparous & 73 & 34.76 & 216 & 34.02 \\
\hline & Multiparous & 120 & 57.14 & 307 & 48.35 \\
\hline \multirow[t]{3}{*}{ Type of current pregnancy } & Wanted and planned & 165 & 78.57 & 515 & 81.10 \\
\hline & Wanted but unplanned & 26 & 12.38 & 70 & 11.02 \\
\hline & Unwanted and unplanned & 19 & 9.05 & 50 & 7.87 \\
\hline \multirow[t]{2}{*}{ ANC visits } & No & 152 & 72.38 & 383 & 60.31 \\
\hline & Yes & 58 & 27.62 & 252 & 39.69 \\
\hline \multirow[t]{4}{*}{ Gestational age } & Previable & 20 & 9.52 & 112 & 17.64 \\
\hline & Preterm & 11 & 5.24 & 37 & 5.82 \\
\hline & Term & 170 & 80.95 & 458 & 72.13 \\
\hline & Post-term & 9 & 4.29 & 28 & 4.41 \\
\hline \multirow[t]{2}{*}{ Duration of labor } & $\leq 18 \mathrm{hr}$ & 48 & 22.86 & 445 & 70.08 \\
\hline & $>18 \mathrm{hr}$ & 162 & 77.14 & 190 & 29.92 \\
\hline \multirow[t]{2}{*}{ Visit type } & Referred & 33 & $|5.7|$ & 86 & 13.54 \\
\hline & Not referred & 177 & 84.29 & 549 & 86.46 \\
\hline \multirow[t]{2}{*}{ Source of referral } & Health center & 20 & 9.52 & 79 & 12.44 \\
\hline & Self-referral & 13 & 6.19 & 7 & 1.10 \\
\hline \multirow[t]{2}{*}{ Intervention } & Medical & 128 & 60.95 & 24 & 3.78 \\
\hline & Surgical & 82 & 39.05 & 611 & 96.22 \\
\hline \multirow[t]{2}{*}{ Duration of hospital stay } & $\leq 7$ days & 99 & 47.14 & 615 & 96.85 \\
\hline & $\geq 8$ days & 111 & 52.86 & 20 & 3.15 \\
\hline \multirow[t]{2}{*}{ Administration-related problems } & yes & 73 & 34.76 & 88 & 13.86 \\
\hline & No & 137 & 65.24 & 547 & 86.14 \\
\hline
\end{tabular}

A study of factors leading to maternal mortality showed the odds of occurrence of maternal near-misses among primipara mother is two times higher than nulliparous women $\quad(\mathrm{AOR}=2.194, \quad 95 \% \quad \mathrm{CI}=1.140-4.223)$. Similarly, the odds of occurrence of maternal near-misses

Table 3 Indicators Proposed by WHO to Describe a Maternal Event in Selected Hospitals in SNNPR, Southwest Ethiopia

\begin{tabular}{|l|l|}
\hline Indicators & $\begin{array}{l}\text { Corresponding } \\
\text { Values }\end{array}$ \\
\hline The absolute number of maternal near-miss & 210 \\
case & \\
Maternal near-miss ratio/ 1000 live births & 37.97 \\
Maternal near-miss-to-maternal death ratio & $12.35: 1$ \\
Mortality ratio/I00,000 live births & 307.41 \\
Mortality index (\%) & 7.48 \\
\hline
\end{tabular}

among multiparous women are 2.5 times higher than nulliparous women $(\mathrm{AOR}=2.561,95 \% \mathrm{CI}=1.364-4.809)$. Controlling for normal duration of labor $(<18$ hours $)$ the odds of occurrence of maternal near-misses among mothers whose labor duration is long ( $>18$ hours) is six times higher than those whose labor is in normal duration (AOR=6.890, 95\% $\mathrm{CI}=4.715-10.066$ ).

The odds of maternal near-miss occurrence among mothers who were given delayed treatment is 1.5 times higher than those who were treated immediately $\mathrm{AOR}=1.561,95 \% \mathrm{CI}=1.031-2.345)$. The odds of maternal near-miss occurrence among mothers who have faced hospital admissions-related problems is twice as high than those who did not (AOR=2.781, 95\% $\mathrm{CI}=1.805-4.286$ ). The odds of occurrence of maternal near-misses is 1.7 times higher among those who did not receive antenatal care follow-up than those who received 


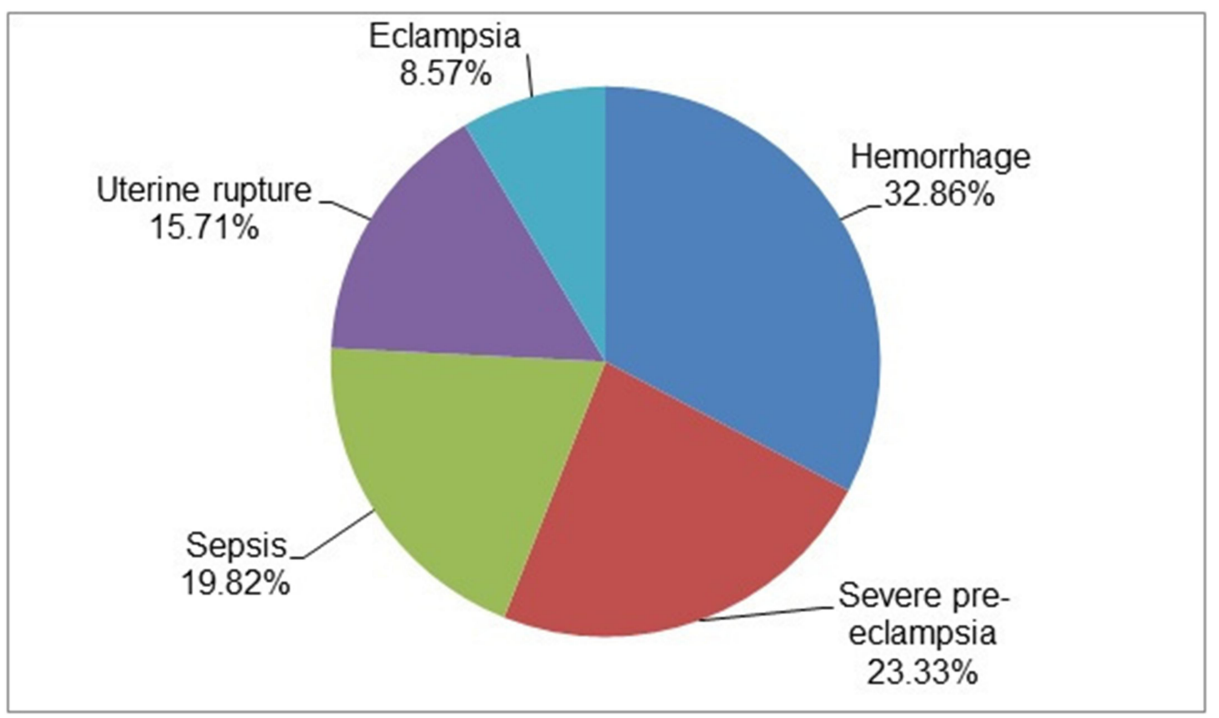

Figure I Maternal near-miss events in selected hospitals of SNNPR, Southwest Ethiopia, 2017.

antenatal care follow-up $\quad(\mathrm{AOR}=1.695, \quad 95 \%$ $\mathrm{CI}=1.127-2.549)$. Regarding the distance between the home of the mother and the health facility, the odds of maternal near-misses is two times higher among mothers home is far from the health center $(>11 \mathrm{~km})$ than those who live near the health center $(<10 \mathrm{~km}$; $\mathrm{AOR}=2.269$, $95 \% \mathrm{CI}=1.335-3.857)$. The odds of maternal near-miss occurrence among mothers who came from a rural area are twice that of those who were from urban areas $(\mathrm{AOR}=2.166,95 \% \mathrm{CI}=1.340-3.500)$ (see Table 5).

\section{Discussion}

The present study revealed an overall proportion of maternal near-miss to be $24.85 \%$. The finding is almost in line with the prevalence of maternal near-misses reported in Campinas, Brazil, in Tanzania, Eastern Sudan Kassala

Table 4 Maternal Mortality Index of Each Cause in Selected Hospitals of SNNPR, Southwest Ethiopia

\begin{tabular}{|l|l|l|l|}
\hline $\begin{array}{l}\text { Near } \\
\text { Miss Event }\end{array}$ & $\begin{array}{l}\text { Number of } \\
\text { Maternal } \\
\text { Died }\end{array}$ & $\begin{array}{l}\text { Number of } \\
\text { Maternal Near- } \\
\text { Miss }\end{array}$ & $\begin{array}{l}\text { Mortality } \\
\text { Index }\end{array}$ \\
\hline $\begin{array}{l}\text { Hemorrhage } \\
\begin{array}{l}\text { Pre- } \\
\text { eclampsia }\end{array}\end{array}$ & 2 & 69 & 10.39 \\
$\begin{array}{l}\text { Sepsis } \\
\text { Uterine } \\
\text { rupture } \\
\text { Eclampsia }\end{array}$ & 2 & 49 & 3.92 \\
\hline
\end{tabular}

hospital and in referral hospitals of Amhara regional state, North Ethiopia which were 15.5\%, 22.9\%, 23.6\%, $22.1 \%$, and $23.3 \%$, respectively. ${ }^{17-20}$ However, it is higher than studies done in Uganda, Nigeria, Brazil, Indonesia, Nepal, and Pakistan which were 10.61\%, 12\%, 15.8\%, $17.3 \%, 2.3 \%$, and $4 \%$, respectively. ${ }^{21-25}$ The higher proportion, when compared to the above studies, is because these three hospitals are the only hospitals that receive critically ill patients from facilities in the zones. In contrast, the proportion is lower when compared with the study done in Accra, Ghana, possibly due to the difference of the criteria used for the identification of the near-miss cases, since that study used the organ-system-based criteria which has a significant effect on the increment of the proportion because the near-miss cases become higher whenever the organ-system-based criteria is used in the setting of a developing country. ${ }^{26}$

Though there is a high proportion of near-misses due to post-partum hemorrhage ( $\mathrm{PPH})$, severe pre-eclampsia, and sepsis the outcome indicators such as maternal near-miss mortality ratio and mortality index were $12.3 \%$ and $7.4 \%$, respectively. As maternal near-misses mortality ratio becomes high and the mortality index becomes low it is an indication that better care is provided to the mother previously suffered from maternal near-misses. This may be due to the availability of currently endorsed, a non-pneumatic, anti-shock garment for $\mathrm{PPH}$, the availability of magnesium sulfate for prevention of eclampsia, and broad-spectrum antibiotics for the management of sepsis, as most near-misses were due to $\mathrm{PPH}$, severe 
Table 5 Factors Associated with Maternal Near-Misses in Selected Public Health Institutions of SNNPR, Southwest Ethiopia

\begin{tabular}{|c|c|c|c|c|c|c|}
\hline \multirow[t]{2}{*}{ Variables } & \multirow[t]{2}{*}{ Categories } & \multicolumn{2}{|c|}{ Near-Misses } & \multirow[t]{2}{*}{ COR $(95 \% \mathrm{Cl})$} & \multirow[t]{2}{*}{ P-value } & \multirow[t]{2}{*}{ AOR $(95 \% \mathrm{Cl})$} \\
\hline & & Yes & No & & & \\
\hline \multirow[t]{3}{*}{ Parity } & Nully (R) & 17 & 112 & I & I & I \\
\hline & Primi & 73 & 216 & $2.27(1.253-3.957)$ & 0.019 & $2.19(1.140-4.223)^{*}$ \\
\hline & Multi & 120 & 307 & $2.58(1.483-4.473)$ & 0.003 & $2.56(1.364-4.809)^{*}$ \\
\hline \multirow[t]{2}{*}{ Duration of labor } & $<18 \mathrm{hrs}(\mathrm{R})$ & 48 & 445 & 1 & 1 & I \\
\hline & $>18 \mathrm{hrs}$ & 162 & 190 & $7.9 \mid$ (5.492-II.377) & 0.000 & $6.89(4.715-10.066)^{*}$ \\
\hline \multirow[t]{2}{*}{ Time of diagnosis } & Short (R) & $|4|$ & 514 & 1 & I & I \\
\hline & Long & 69 & 121 & $2.08(1.466-2.948)$ & 0.032 & $1.56(1.039-2.345)^{*}$ \\
\hline \multirow[t]{2}{*}{ Administration-related problem } & Yes & 73 & 88 & 3.31 (2.305-4.759) & 0.000 & $2.78(1.805-4.286)^{*}$ \\
\hline & No $(R)$ & 137 & 547 & I & I & I \\
\hline \multirow[t]{2}{*}{ ANC follow-up } & Yes (R) & 58 & 252 & I & I & I \\
\hline & No & 152 & 383 & $1.72(1.225-2.427)$ & 0.011 & $1.7(1.127-2.549)^{*}$ \\
\hline \multirow[t]{2}{*}{ Distance of living place from hospital } & Near (R) & 47 & 196 & 1 & I & I \\
\hline & Far & 163 & 439 & $1.55(1.074-2.232)$ & 0.002 & $2.27(1.335-3.857)^{*}$ \\
\hline \multirow[t]{2}{*}{ Residence } & Urban (R) & 126 & 411 & 1 & 1 & I \\
\hline & Rural & 84 & 224 & $1.22(0.888-1.685)$ & 0.002 & $2.17(1.340-3.500)^{*}$ \\
\hline
\end{tabular}

Note: * P-value $<0.05$

Abbreviations: AOR, adjusted odds ratio; $\mathrm{COR}$, crude odds ratio; $\mathrm{Cl}$, confidence interval; $\mathrm{R}$, reference category.

pre-eclampsia, and sepsis. But blood banks and intensive care units (ICU) which might play a role in preventing lifelong complications were absent in the health institutions which increases the complexity of the problem. In this study, the parity of the mothers was found to be significantly associated with the occurrence of maternal near-misses. The odds of maternal near-misses among primiparous and multiparous women were twice as high when compared with nulliparous women. This might be partly explained by the fact that obstetric complications increase with a higher number of pregnancies. Regarding the duration of labour, mothers whose labour persisted $>18$ hours (prolonged) are nearly seven times more likely to develop near-misses than those whose labour stayed under 18 hours (normal duration). This is because during prolonged labour the uterus may become exhausted and the uterine muscles may lose their integrity, which predisposes women who are multiparous to uterine rupture and those who are primigravida to fistulas. The time gap between diagnosis and treatment is one of the factors which have a statistically significant association with the occurrence of maternal nearmisses. Women whose time gap between diagnosis and treatment is longer are almost 1.5 times higher than those who have a short gap. This finding is consistent with the study done in Uganda. ${ }^{23}$ The odds of occurrence of maternal near-misses among mothers who have faced an admission-related problem like lack of life-saving drugs in hospital pharmacy and nonavailability of blood products for transfusion in the hospitals were 2.7 times higher when compared with those who did not face these issues. Since most maternal near-misses were due to PPH and unavailability of blood products for transfusion can lead to the development of serious complications. This result is consistent with the study done in Gambia's referral hospital and at the University of Illinois, Chicago. ${ }^{27,28}$

Antenatal care follow-up was also found to be significantly associated with maternal near-misses. The odds of occurrence of near-miss events among women who did not receive antenatal care follow-up during their pregnancy is 1.7 times higher than those who have had antenatal care follow-up. Lack of antenatal follow-ups can result in loss of information about anticipating labour and its signs, better sites for delivery and when to seek professional help rather than managing at home. This finding is consistent with other studies done which were in Ethiopia, Nigeria, Pakistan, Bangladesh and Bolivia. ${ }^{29-32}$

Distance to the health facility from home causing potential delays in reaching the health facility is also one of the variables which showed to have a statistically significant association with maternal near-misses. The odds of occurrence of near-miss events among mothers who lived far from the health center $(>11 \mathrm{~km})$ is 2.27 times higher than those 
mothers who lived nearby $(<10 \mathrm{~km})$. Delays in receiving adequate medical care can lead to the development of severe complications during and after childbirth. This finding is consistent with the studies conducted in southeast Ethiopia, Tigray region, northern Ethiopia, and Nigeria. ${ }^{25,33}$

Regarding residential data, the odds of developing nearmisses among mothers who live in rural areas are two times higher than those who live in urban localities. This might be due to the decreased performance of the health workers in rural areas, who are used as a bridge between the health facilities and the rural population. If the health workers are unable to provide adequate quality of care, rural women might lack access to health education, promotion, and services. This finding is consistent with the study done in referral hospitals of Amhara Regional State and Arsi zone of southeast Ethiopia. ${ }^{20,33}$

\section{Conclusion}

In conclusion, the incidence proportion of maternal nearmiss is relatively high in the selected hospitals. But, the outcome indicators and outcome measures seem to suggest optimum care is being given to mothers who suffered from the life-threatening condition and this has subdued maternal mortality. The most important factors which showed to have a statistically significant association with maternal near-misses were diverse in nature. Being primipara, multiparity, persisted labour duration, delays between diagnosis and treatment, lack of ANC follow-up, presence of administration-related problems, being in rural residence, and living far from the health institution. We strongly recommend studying cultural malpractice in the study area and its consequence concerning maternal health.

\section{Limitation of the Study}

Disease-specific criteria were used to identify maternal near-miss events which are less stringent than other clinical criteria; as a result, the probability of over-reporting cases could happen. Verification of cases was done by different physicians so that subjective miss diagnosis cannot be completely ruled out. Information is elicited retrospectively; hence, recall bias could affect the quality of data. A cross-sectional study design was employed, it may have temporal ambiguity.

\section{Abbreviations}

SPSS, Statistical Solution and System Package; CI, confidence Interval; AOR, adjusted odds ratio; COR, crude odds ratio; LB, live birth; ANC, antenatal care; WHO, World Health Organization; EDHS, Ethiopian
Demographic Health Survey; WLTC, women with lifethreatening conditions; MNM, maternal near-misses; MD, maternal death; SAMM, severe acute maternal morbidity; HEELP, hemolysis elevated enzyme low platelet; SMOR, severe maternal outcome ratio; MI, mortality index; PPH, postpartum hemorrhage; ICU, intensive care unit; LNMP, last normal menstrual period; MVA, manual vacuum aspiration; IESOC, Integrated Emergency Surgery and Obstetric Care; SNNPR, Southern Nations, Nationalities, and People's Region.

\section{Data Sharing Statement}

The datasets supporting the conclusions of this article are included within the article and its additional files.

\section{Ethical Approval and Consent}

This study was conducted in accordance with the declaration of Helsinki. Ethical approval was obtained from Mizan Tepi University ethical review board, the official permission was obtained from the selected hospital. After the objectives of the study were explained and participants were informed that they had full right to withhold information, skip questions, or to withdraw from the study at any time, informed written consent was obtained from them. For participants under the age of sixteen, we obtained written informed consent from their parents or guardian. The consent process for this study was approved by the Mizan Tepi University Ethical Review Board.

\section{Acknowledgment}

We would like to address our gratitude to our colleagues for the effort they made to enrich our Research with an important guide and input. We are thankful to Mizan-Tepi university Midwifery department staff for their continuous support and follow-up from developing this proposal to the end of the finding. We are also thankful for our data collectors and study participants. Also, we would like to acknowledge BenchMaji, Keffa, and Sheka zone Health Bureau staff for their unlimited cooperation of sharing valuable data when needed which lay a base for the finalization of this research finding.

\section{Authors' Information}

Yayehyirad Yemaneh Adinew (MSc in Clinical Midwifery), lecturer in Mizan-Tepi University College of Health Sciences, Department of Midwifery; Firew Tiruneh Tiyare (MSc in Child Health), lecturer in Mizan-Tepi University College of Health Sciences, Department of Midwifery. 


\section{Author Contributions}

All authors made substantial contributions to conception and design, acquisition of data, or analysis and interpretation of data; took part in drafting the article or revising it critically for important intellectual content; agreed to submit to the current journal; gave final approval of the version to be published; and agree to be accountable for all aspects of the work.

\section{Funding}

The funding for this study was covered by Mizan-Tepi University. The role of Mizan-Tepi University was to evaluate the protocol, supervised the data collection, and to review the study report.

\section{Disclosure}

The authors report no conflicts of interest for this work.

\section{References}

1. Trends in maternal mortality: 2000 to 2017 UNFPA United Nations population fund [Internet]; Cited Sep 6, 2020. Available from: https:// www.unfpa.org/featured-publication/trends-maternal-mortality-2000 2017. Accessed November 26, 2020.

2. Maternal health [Internet]. Available from: https://www.who.int/ health-topics/maternal-health\#tab=tab_1. Accessed Sep 6, 2020

3. 404 [Internet]. Available from: https://www.who.int/news-room/factsheets/detail/maternal-mortality. Accessed Sep 6, 2020.

4. Munjanja SP. Joining the dots: a plea for precise estimates of the maternal mortality ratio in sub-Saharan Africa. BJOG. 2009;116:7-10. doi:10.1111/j.1471-0528.2009.02337.x.

5. Say L, Pattinson RC, Gülmezoglu AM. WHO systematic review of maternal morbidity and mortality: the prevalence of severe acute maternal morbidity (near miss) [Internet]. Reproductive Health BioMed Central. 2004;1(3). cited http://reproductive-health-journal. biomedcentral.com/articles/10.1186/1742-4755-1-3. 2020.

6. Can enquiries into severe acute maternal morbidity act as a surrogate for maternal death enquiries. Pub Med. 2020.

7. Filippi V, Brugha R, Browne E, et al. Obstetric audit in resource-poor settings: lessons from a multi-country project auditing "near miss" obstetrical emergencies. Health Policy Plan. 2004;19(1):57-66. doi:10.1093/heapol/czh007

8. Say L, Souza JP, Pattinson RC. Maternal near miss - towards a standard tool for monitoring quality of maternal health care. Best Pract Res Clin Obstet Gynaecol. 2009;23(3):287-296. doi:10.1016/j. bpobgyn.2009.01.007

9. Fragile States Index. The fund for peace [Internet]; cited Sep 6, 2020. Available from: https://fragilestatesindex.org/. Accessed November 26, 2020.

10. Ethiopia demographic and health survey; 2011. Available from: https://microdata.worldbank.org/index.php/catalog/1381/relatedmaterials. Accessed Sep 13, 2020.

11. Field listing:: maternal mortality rate the world factbook - central intelligence agency [Internet]; cited Sep 6, 2020. Available from: https://www.cia.gov/library/publications/the-world-factbook/fields/ 353.html. Accessed November 26, 2020.

12. Sustainable development goal 3: good health and well-being | united Nations in Ethiopia [Internet]; cited Sep 6, 2020. Available from: https://ethiopia.un.org/en/sdgs/3. Accessed November 26, 2020.
13. Kumela L, Tilahun T, Kifle D Determinants of maternal near miss in Western Ethiopia. Ethiop J Health Sci [[2020];30(2):161-168.

14. Yeman A, Teka H, Zelelow YB, Mohammednur S, Goba G, George J. Maternal near miss at a tertiary teaching hospital in Mekelle, Ethiopia [21L]. Obstet Gynecol. 2020;;135:129S. doi:10.1097/01.AOG.0000664632.68283.72

15. Geleto A, Chojenta C, Taddele T, Loxton D. Incidence of maternal near miss among women in labour admitted to hospitals in Ethiopia. Midwifery. 2020;1(82):102597. doi:10.1016/j.midw.2019.102597

16. Wang J, Ge G, Fan Y, et al. The estimation of sample size in multi-stage sampling and its application in medical survey. Appl Math Comput. 2006;178(2):239-249.

17. Adisasmita A, Deviany PE, Nandiaty F, Stanton C, Ronsmans C. Obstetric near miss and deaths in public and private hospitals in Indonesia. BMC Pregnancy Childbirth. 2008;8(1):1-9. doi:10.1186/ 1471-2393-8-10

18. Tunçalp Ö, Hindin MJ, Adu-Bonsaffoh K, Adanu RM. Assessment of maternal near-miss and quality of care in a hospital-based study in Accra, Ghana. Int $J$ Gynecol Obstet. 2013;123(1):58-63. doi:10.1016/j.ijgo.2013.06.003

19. Nelissen EJT, Mduma E, Ersdal HL, Evjen-Olsen B, van Roosmalen JJM, Stekelenburg J. Maternal near miss and mortality in a rural referral hospital in northern Tanzania: a cross-sectional study. BMC Pregnancy Childbirth. 2013;13(1):141. doi:10.1186/ 1471-2393-13-141

20. Tatek Abate MD. Proportion of maternal near misses and associated factors in referral hospitals of Amhara regional state, Northwest Ethiopia: institution based cross sectional study. Gynecol Obstet. 2015;05(08):1-8. doi:10.4172/2161-0932.1000308

21. Shrestha NS, Saha R, Karki C. Near miss maternal morbidity and maternal mortality at Kathmandu Medical College Teaching Hospital. Kathmandu Univ Med J. 2010;8(30):222-226. doi:10.3126/kumj. $\mathrm{v} 8 \mathrm{i} 2.3563$

22. Nelissen EJT, Mduma E, Ersdal HL, Evjen-Olsen B, van Roosmalen JJM, Stekelenburg J. Maternal near miss and mortality in a rural referral hospital in northern Tanzania: a cross-sectional study. BMC Pregnancy Childbirth []. 2013 [];13(1):141.

23. Kaye D, Mirembe F, Aziga F, Namulema B. Maternal mortality and associated near-misses among emergency intrapartum obstetric referrals in Mulago Hospital, Kampala, Uganda. East Afr Med J. 2003;80 (3):144-149.

24. Ali AAA, Khojali A, Okud A, Adam GK, Adam I Maternal near-miss in a rural hospital in Sudan. BMC Pregnancy Childbirth []. 2011 [];11(1):48. doi:10.1186/1471-2393-11-48

25. Gebrehiwot Y, Tewolde BT. Improving maternity care in Ethiopia through facility based review of maternal deaths and near misses. Int $J$ Gynecol Obstet. 2014;127(S1):S29-34. doi:10.1016/j. ijgo.2014.08.003

26. Oladapo OT, Sule-Odu AO, Olatunji AO, Daniel OJ. "Near-miss" obstetric events and maternal deaths in Sagamu, Nigeria: a retrospective study. Reprod Health. 2005;2(1):9.

27. Nair M, Kurinczuk JJ, Brocklehurst P, Sellers S, Lewis G, Knight M. Factors associated with maternal death from direct pregnancy complications: a UK national case-control study. BJOG an Int J Obstet Gynaecol. 2015;122(5):653-662. doi:10.1111/14710528.13279

28. Cham M, Sundby J, Vangen S. Availability and quality of emergency obstetric care in Gambia's main referral hospital: women-users' testimonies. Reprod Health. 2009;6(1). doi: 10.1186/1742-4755-6-5

29. Mustafa R, Hashmi H. Near-miss obstetrical events and maternal deaths. J Coll Physicians Surg Pak. 2009;19(12):781-785.

30. Oladapo OT, Lamina MA, AO SULE-ODU. Maternal morbidity and mortality associated with elective Caesarean delivery at a university hospital in Nigeria. Aust New Zeal J Obstet Gynaecol []. 2007 [];47 (2):110-114. doi:10.1111/j.1479-828X.2007.00695.x 
31. Sikder SS, Labrique AB, Ullah B, et al. Accounts of severe acute obstetric complications in rural Bangladesh. BMC Pregnancy Childbirth. 2020:11(1); 76

32. Rööst M, Altamirano VC, Liljestrand J, Essén B. Does antenatal care facilitate utilization of emergency obstetric care? A case-referent study of near-miss morbidity in Bolivia. Acta Obstet Gynecol Scand. 2010;89(3):335-342. doi:10.3109/00016340903511050
33. Abera M, Gebremariam A, Belachew T. Predictors of safe delivery service utilization in Arsi Zone, South-East Ethiopia. Ethiop J Health Sci. 2011;21(Suppl 1):95-106.

\section{Publish your work in this journal}

The International Journal of Women's Health is an international, peerreviewed open-access journal publishing original research, reports, editorials, reviews and commentaries on all aspects of women's healthcare including gynecology, obstetrics, and breast cancer. The manuscript management system is completely online and includes a very quick and fair peer-review system, which is all easy to use. Visit http://www.dovepress.com/testimonials.php to read real quotes from published authors. 